\title{
Depressed mood induction in early cigarette withdrawal is unaffected by acute monoamine precursor supplementation
}

This article was published in the following Dove Press journal:

Neuropsychiatric Disease and Treatment

\author{
Yekta Dowlati ${ }^{1,2}$ \\ Danilo R de Jesus ${ }^{1,2}$ \\ Peter Selby ${ }^{1-3}$ \\ Ian Fan ${ }^{2,4}$ \\ Jeffrey $\mathrm{H}$ Meyer ${ }^{1,2}$
}

'CAMH Research Imaging Centre and Campbell Family Mental Health Research Institute, Centre for Addiction and Mental Health, Toronto, ON, Canada; ${ }^{2}$ Department of Psychiatry, University of Toronto, ON Canada; ${ }^{3}$ Department of Family and Community Medicine, University of Toronto, Toronto, ON, Canada; ${ }^{4}$ Mood Disorders Association of British Columbia, Vancouver, BC, Canada
Correspondence: Jeffrey H Meyer CAMH Research Imaging Centre, 250 College Street, Toronto, ON M5T IR8, Canada

Tel +l 416535850 I (ext 34007)

Fax + I 4169794656

Email jeff.meyer@camhpet.ca
Background: Cigarette smoking is the leading preventable cause of death; however, quitting is difficult and early relapse is common. Dysphoric mood during early cigarette withdrawal is associated with relapse, and with the exception of bupropion and nortriptyline, few interventions have been developed to prevent this. During early cigarette withdrawal there is an elevation in the levels of monoamine oxidase-A (MAO-A), which removes monoamines excessively and induces oxidative stress and is implicated in creating sad mood. Hence, we conducted a randomized, placebo-controlled, double-blind crossover trial of a dietary supplement designed to counter the effects of elevated MAO-A levels on vulnerability to depressed mood.

Methods: Twenty-one otherwise healthy cigarette smokers completed the protocol, receiving either active dietary supplement followed by washout and placebo or the same in reverse order. The dietary supplement was composed of monoamine precursors ( $2 \mathrm{~g}$ tryptophan, $10 \mathrm{~g}$ tyrosine) and blueberry antioxidants (blueberry juice with blueberry extract). Vulnerability to depressed mood was measured by the change in scores of depressed mood on the visual analog scale (VAS) following the sad mood induction paradigm (MIP).

Results: There was a significant increase in VAS depressed mood scores after the sad MIP during supplement and placebo, but no difference between active and placebo conditions. There was also a significant increase in urge-to-smoke scores after sad MIP during supplement and placebo but no difference between active and placebo conditions. Reliability of the increase in VAS after MIP was very good.

Conclusion: The dietary supplement had negligible effect on depressed mood, but sad MIP is a very reliable method that can be applied in future studies to assess other interventions for preventing dysphoric mood during early cigarette withdrawal.

Keywords: cigarette withdrawal, dysphoria, dietary supplement, mood induction, monoamines

\section{Introduction}

WHO ranks cigarette smoking as the leading preventable cause of death worldwide. ${ }^{1,2}$ Quitting is difficult and $\sim 50 \%$ of people relapse within the first 3 days of cigarette cessation. ${ }^{3,4}$ The symptoms of early cigarette withdrawal are associated with resumption of cigarette smoking. 5,6 Among these symptoms, dysphoric mood is important because it starts as early as 4 hours into cigarette cessation and is individually, strongly predictive of relapse..$^{5-9}$

Most interventions, evaluated for their prevention of dysphoric mood in early cigarette withdrawal, were studied in subjects with a history of major depressive disorder (MDD). An advantage of this approach is that history of MDD is associated with more severe dysphoria during withdrawal ${ }^{10}$ but a disadvantage is that there is a paucity of 
investigations that include cases without past MDD. A doubleblind randomized placebo controlled trial of sertraline found no effect of treatment on depressed mood or abstinence rates 1 week after smoking cessation or abstinence rates but found significantly less irritability, anxiety, craving and restlessness in those receiving sertraline compared to placebo. ${ }^{11}$ Another double-blind randomized controlled trial of placebo, $20 \mathrm{mg}$, or $40 \mathrm{mg}$ fluoxetine in addition to cognitive behavioral therapy (6 weeks) and nicotine patch (10 weeks) found that fluoxetine had a moderate effect on lowering withdrawal symptoms as measured by Minnesota Tobacco Withdrawal Symptoms Checklist in both groups as compared to placebo, but no targeted effect on mood and did not significantly improve smoking cessation rates. ${ }^{12}$ Nortriptyline was shown to reduce the negative effect over the first 8 days of smoking cessation, as measured by the profile-of-mood-state total mood disturbance score (POMS-TMD), and improve abstinence rates over 64 weeks, which was predicted by the level of depressed mood in early withdrawal. ${ }^{13} \mathrm{~N}$-acetylcysteine administration in a small pilot study was associated with higher positive effect compared to placebo during early smoking abstinence, ${ }^{14}$ though another study found no effect on withdrawal symptoms. ${ }^{15}$ One report of oral tryptophan with a high carbohydrate diet was associated with lower withdrawal symptoms in subjects undergoing behaviorally oriented smoking cessation treatment in early smoking withdrawal, but depressive symptoms were unaffected. ${ }^{16}$ Bupropion was shown in several studies to alleviate depressive and other withdrawal symptoms. ${ }^{17-19}$ However, even with bupropion treatment, subjects often experience depressed mood during early withdrawal with effect sizes of change towards depressed mood being $\sim 0.5-1$. Overall, most pharmacotherapy intervention studies targeting depressed mood during cigarette cessation evaluated antidepressants, with only bupropion demonstrating benefit in a moderate proportion of cases.

The effects of cigarette smoking are complex, and there are multiple mechanisms implicated in the occurrence of depressed mood during cigarette withdrawal. Ascending mesolimbic dopamine pathways from the ventral tegmental area (VTA) are modulated by several systems including cholinergic and glutaminergic projections from the tegmental pedunculopontine nucleus as well as GABA releasing neurons of the VTA. With chronic nicotine use, the modulation of these systems may be altered, shifting the influence of nicotine from GABA releasing neurons towards DA releasing neurons, facilitating increased activity of the mesolimbic DA pathway, and leading to psychological symptoms of craving and withdrawal. ${ }^{20}$ There is also longstanding evidence that hypercholinergic states may lead to depression, such as through increased acetylcholine levels from organophosphate poisoning in humans, and greater nicotinic acetylcholine receptor affinity in Flinders Sensitive Line rats. ${ }^{21}$ Also, nicotinic antagonists may reduce depressed mood. ${ }^{21}$

A relatively recent biological mechanism also implicated in the dysphoric mood of early cigarette withdrawal is the elevation in monoamine oxidase A (MAO-A) levels in those who smoke heavily. ${ }^{22-24}$ The B-carbolines harman and norharman are found in cigarette smoke and bind with high affinity to MAO-A, inhibiting it both in the brain and periphery during active smoking. ${ }^{22-24}$ During early withdrawal, lower levels of $\mathrm{B}$-carbolines are associated with a rise in available MAO-A binding sites. ${ }^{22}$ Moreover, the increase in MAO-A binding sites in the prefrontal and anterior cingulate cortex was correlated with a shift to depressed mood between active smoking and withdrawal. Elevated MAO-A levels are consistently associated with depressed mood across a number of illnesses and conditions, including major depressive episodes (MDE), prior to recurrence of MDE, and perimenopause. ${ }^{25-28} \mathrm{MAO}-\mathrm{A}$ level is highly correlated with MAO-A activity in the brain, and MAO-A metabolizes monoamines such as serotonin, norepinephrine and dopamine, which support the functioning of neural structures underlying a healthy mood state. ${ }^{29-31}$

The aim of this randomized double blind placebo controlled cross-over study was to determine if a new dietary supplement combination designed to counter effects of greater MAO-A levels during early cigarette withdrawal reduces vulnerability to depressed mood compared to placebo. The dietary supplement was composed of tyrosine, tryptophan and natural blueberry extract with blueberry juice. Tyrosine is an amino acid precursor to norepinephrine and dopamine, and tryptophan is a precursor amino acid for serotonin. Manipulations of tryptophan and tyrosine levels in plasma through dietary challenges may affect release of serotonin, dopamine and, to a lesser extent norepinephrine in rodent brain and may affect depressed mood in humans. ${ }^{32-35}$ Blueberry juice and extract contains anthocyanins, which are dietary antioxidants and were added to counter prooxidant effects of elevated MAO-A. Most investigations of blueberry anthocyanins in rodents and pigs suggest that they cross the blood brain barrier. ${ }^{36-38}$ It was hypothesized that administration of the dietary supplement would generate increased resiliency against induction of depressed mood in early cigarette withdrawal. Induction of depressed mood was chosen as a key outcome variable because it controls and incorporates environmental influences, is associated with vulnerability towards mood disorders, and the methods are well 
standardized. Some studies have also shown that the effects of sad mood induction on increased smoking motivation is heightened in depressed smokers. ${ }^{39,40}$ In this study, mood induction procedure (MIP) was used to induce vulnerability to sadness in subjects in early cigarette withdrawal.

\section{Methods}

\section{Study design and study participants}

Healthy volunteers (aged 18-65 years), who reported smoking at least a half a regular pack (20 cigarettes per pack) of cigarettes per day regularly, were recruited through advertisement. All had reported a past history of smoking a pack a day. Sixty-six percent of subjects had tried to quit cigarette smoking in the past. Inclusion criteria included: report of stable, good, current physical health, a normal physical examination, and ability to give informed consent. Exclusion criteria were recent history of myocardial infarction and/or stroke, any current substance use disorder except for nicotine, and current diagnosis of MDD (based on Hamilton Depression Rating Scale [HDRS]>7).

This study was approved by the Research Ethics Board for Human Subjects at the Center for Addiction and Mental Health (CAMH), Toronto, Canada and the Natural Health Product Directorate and Drug Directorate of Health Canada. All subjects provided written informed consent after a thorough explanation of the study. Participation was voluntary and each participant was free to withdraw anytime during the study. All experiments on human subjects were conducted in accordance with the Declaration of Helsinki and the International Conference on Harmonization Good Clinical Practice guidelines. (ClinicalTrials.gov, Identifier: NCT02042521).

Participants came in for three visits, which included a screening session and 2 active study days, at least 1 week apart. During the screening visit the subjects completed a standardized medical history, a urine drug screen to rule out current substance abuse, the Fagerstrom Test for Nicotine Dependence, ${ }^{41,42}$ the Nicotine Dependence Syndrome Scale, ${ }^{43}$ and the HDRS. A record of the brand of cigarettes smoked, number of cigarettes smoked per day in the past and currently, and the number of years they had been smoking cigarettes was obtained. Also, exhaled $\mathrm{CO}$ levels were measured at screening and a cutoff of $10 \mathrm{ppm}$ was applied (Bedfont Scientific Ltd., Kent, England) ${ }^{44}$ For women, a pregnancy test was also done during the first visit.

\section{Main study procedure}

After screening, subjects were randomized for receiving dietary supplement, then washout then placebo or placebo then washout then dietary supplement. Randomization was done by computer generated fixed block model performed by an independent company (National Sanitation FoundationGuelph Food Technology Center [NSF-GFTC]) and the placebo matched the active dietary supplement in taste and color. On each active study day, subjects were asked to refrain from smoking cigarettes for 8 hours (Figure 1). Exhaled CO levels were also measured within $\sim 4.5$ hours of the first measurement on each active study day (at 7:30 AM and 12:15 PM). After 5 hours of withdrawal, subjects underwent a sad MIP (see complete description below). Mood symptoms and symptoms of cigarette withdrawal obtained during and after the MIP were compared between the 2 different days.

\section{Dietary supplement}

The dietary supplement consisted of a morning and an evening serving. The key ingredients of the active evening dietary supplement were $2 \mathrm{~g}$ of tryptophan, $280 \mathrm{~mL}$ of blueberry juice

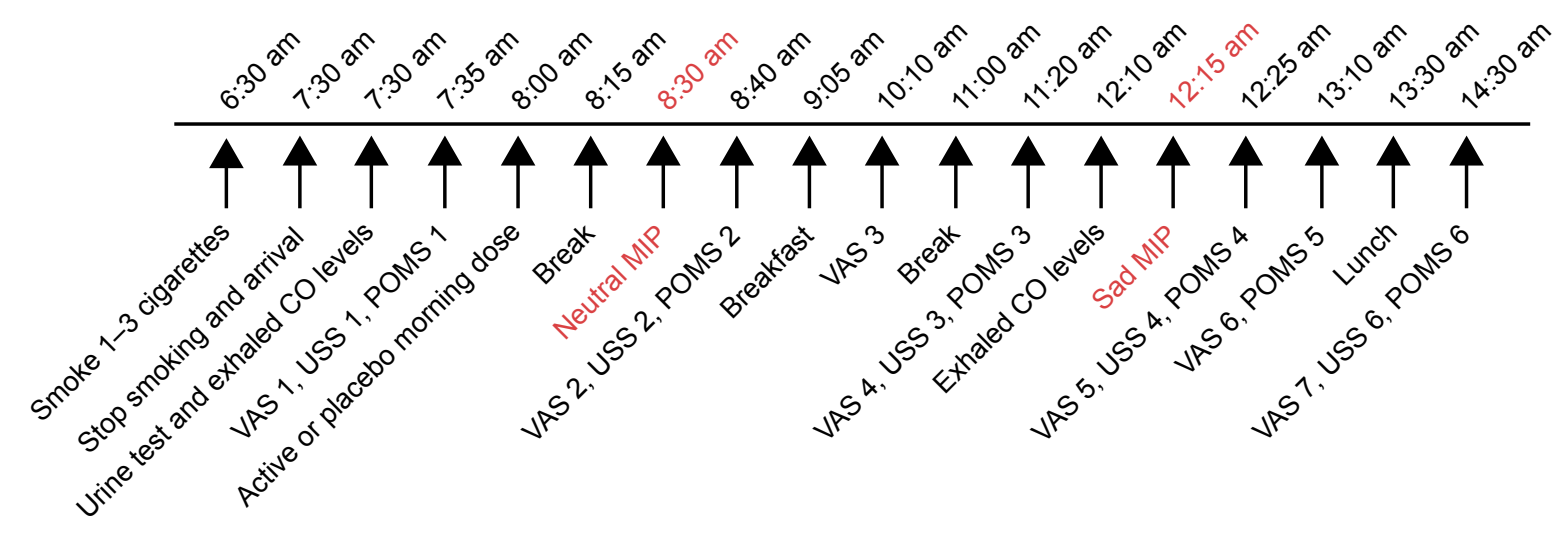

Figure I Timing of VAS, USS and POMS relative to MIP.

Abbreviations: MIP, mood induction procedure; VAS, visual analog scale; USS, urge to smoke scale; POMS, profile-of-mood-state. 
and $1 \mathrm{~g}$ of blueberry extract. The key ingredients of the active morning dietary supplement were $10 \mathrm{~g}$ of tyrosine totaling $10 \mathrm{~g}, 280 \mathrm{~mL}$ of blueberry juice and $1 \mathrm{~g}$ of blueberry extract. Tryptophan was given in the evening before an active study day and tyrosine was given on the morning of an active study day, with a separation of at least 8 hours to avoid competition at the Large Neutral Amino Acids Transporters for transport though the blood-brain-barrier. The 1-tryptophan capsules of $1 \mathrm{mg}$ were obtained from Apotex (Apo-tryptophan by Apotex Incorporated, Toronto, Canada, Drug Identification Number [DIN]\# 02248539). Tyrosine capsules of $500 \mathrm{mg}$ were obtained from Trophic Canada (Trophic Canada, Richmond Hill, Canada, NPN\#80010004). The blueberry extract powder called VitaBlue, was obtained from Future-Ceuticals (Future Ceuticals, Momence, IL, USA) and prepared and packaged by NSF-GFTC, in sachets containing $1 \mathrm{~g}$. Blueberry juice was obtained from Milne Fruit Products and packaged by GFTC in $280 \mathrm{~mL}$ bottles. The blueberry juice and extract were designed to be mixed at the time of ingestion. Blueberry extracts were added to the juice, since the anthocyanins in blueberry juice are mostly damaged during pasteurization. Placebo blueberry juice and extract were designed and prepared by NSF-GFTC and placebo tryptophan and tyrosine were prepared by the local CAMH pharmacy. The placebo pills appeared identical to tryptophan and tyrosine pills. The placebo drink and extract were a natural drink and powder that were blue due to natural coloring, had a blueberry flavor through natural flavoring, had negligible antioxidant properties and had sugar levels similar to that of to the active drink and extract.

\section{Measures}

Mood symptoms and symptoms of cigarette withdrawal were compared between the 2 different days and were measured before and after the sad MIP on each visit (Figure 1). For measuring mood, a $10-\mathrm{cm}$ visual analog scale (VAS) was used. VAS uses a 10-point scale for participants to indicate the extent to which each of the items indicated is consistent with how they feel at that moment, ranging from most happy to most depressed. In addition, there were VAS scales labeled from left to right from most energy to least energy, and least anxious to most anxious. Other questionnaires included were the short form 37-item of POMS scale, and the urge to smoke scale (USS), an analog scale, with 10 craving-related questions.

\section{Assessment of vulnerability to depressed mood induction}

During each active study day, the participants underwent a neutral MIP and a sad MIP. The first neutral MIP was applied to reduce environmental effects on mood. The MIP applied the Velten ${ }^{45}$ method in combination with the approach of Clark. ${ }^{46}$ The Velten method is the most widely used technique for studying affective influences upon behavior and has demonstrated effectiveness in altering subjective emotional states. Velten MIP is a series of 60 self-referent statements. Negative statements reflect pessimism, dissatisfaction, and lethargy; for example "life is a heavy burden." Neutral statements reflect a lack of mood effect; for example, "an orange is a citrus fruit." Subjects were asked to read each statement, printed individually, first to themselves and then aloud, and to "feel and experience each statement as it would apply to you personally." For the method of Clark, ${ }^{46}$ to facilitate the MIP, participants were also presented with a piece of music while reading the statements. For sad MIP, subjects listened to Prokofiev's "Russia under the Mongolian Yoke" and for neutral MIP, subjects listened to Mozart's "Piano Concerto No 21 in C Major."

MIP is well known to induce a temporary depressed mood state in healthy humans as well as in recovered states from mood disorders. MIP can act as an advanced form of mood rating where the environmental conditions are standardized. To obtain a maximal percentage of responders to mood induction in this study, a combination of the Velten and the musical MIP was used in this study. ${ }^{45,46}$ The Velten and Clark methods are common in mood disorders field although this is their first application together to assess mood during early cigarette withdrawal.

\section{Monitoring for compliance}

Compliance monitoring of the evening supplement was done with riboflavin fluorescence. Along with all the active or placebo dietary supplements, a pill of riboflavin (100 mg), which was identical in appearance to the tryptophan capsules, was given to the subjects. The subjects were notified that riboflavin was included in the dietary supplements, but they were not told which pill contained riboflavin. The urine sample taken on the day of the MIP was subjected to ultraviolet light to check for riboflavin fluorescence to verify compliance. The morning supplement was taken in the presence of the research study personnel.

\section{Data analytic plan}

First, a within subject $t$-test was done to assess whether there was an effect of the sad MIP on VAS depressed mood scores in both the active and placebo conditions by comparing the VAS depressed mood scores pre-MIP (VAS 4) and post sad MIP (VAS 5). Then, the change in VAS depressed mood scores, immediately before and after the sad MIP, was 
calculated (ie, the change in VAS scores from VAS 4 to 5) and applied in several subsequent analyses as follows. A repeatedmeasures ANOVA (rmANOVA) (considering the repeated visit as the repeated measure) was performed to compare the effect of the dietary supplement vs placebo and assess the effect of the order (supplement given with the first or second MIP). In the event that the primary outcome was negative, that is, no effect of the supplement on change in VAS scores of depressed mood, it was decided that test-retest reliability between the VAS depressed mood change scores on the first depressed MIP visit and the second depressed MIP visit would be assessed with the intraclass correlation coefficient (ICC).

In addition, a within subject $t$-test was done to assess whether there was an effect of the sad MIP on USS scores in both the active and placebo conditions by comparing the USS scores pre MIP (USS 3) and post sad MIP (USS 4). Then, the change in USS scores, immediately before and after the sad MIP, was calculated and applied in several subsequent analyses as follows. A rmANOVA was performed to compare the effect of the dietary supplement vs placebo and assess the effect of the order (supplement given with the first or second MIP).

\section{Results}

The mean age of the samples was $43.73 \pm 12.28$ years and on average, participants smoked $19.81 \pm 5.06$ cigarettes per day. The demographics and clinical characteristics of the subjects are presented in Table 1. Riboflavin was detected positive through visual urine fluorescence technique in all subjects.

\section{Effect of dietary supplement on depressed mood after MIP}

There was a significant increase in VAS depressed mood scores (VAS4 to VAS5) after the sad MIP during supplement (mean \pm SD: $1.56 \pm 2.09 \mathrm{~cm}, t[20]=3.43, P=0.003$ ) and

Table I Demographic and clinical characteristics

\begin{tabular}{|l|l|}
\hline Measures & Mean \pm SD or $\%$ \\
\hline Age (years) & $43.73 \pm 12.28$ \\
\hline Sex (male) & $38.02 \%$ \\
\hline Duration of smoking (years) & $23.63 \pm 12.56$ \\
\hline Average number of cigarettes smoked per day & $19.81 \pm 5.06$ \\
\hline HAM-D scores ${ }^{\mathrm{a}}$ & $1.4 \pm 2.14$ \\
\hline Exhaled carbon monoxide levels ${ }^{\mathrm{a}}$ & $23.19 \pm 14.79$ \\
\hline Fagerstrom test for nicotine dependence ${ }^{\mathrm{a}}$ & $4.85 \pm 2.03$ \\
\hline $\begin{array}{l}\text { Nicotine dependence syndrome scale } \\
\text { (overall score) }\end{array}$ & $-0.48 \pm 0.65$ \\
\hline Riboflavin positive urine detection & $100 \%$ \\
\hline
\end{tabular}

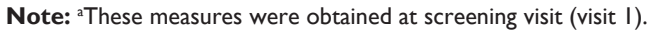

Abbreviation: HAM-D, Hamilton depression rating scale. placebo (mean \pm SD: $1.12 \pm 1.81 \mathrm{~cm}, t[20]=2.84, P=0.01$ ). Visual inspection of the plot of depressed mood over time indicated that the increase in depressed mood occurred primarily between time point four (corresponding to 55 minutes prior to MIP and 3 hours and 50 minutes into cigarette withdrawal) and (corresponding to 10 minutes post MIP and 4 hours and 55 minutes into cigarette withdrawal), with a decline in depressed mood after time point 5 (see Figure S1). rmANOVA showed that the change in VAS scores of depressed mood in the placebo and active conditions did not differ significantly $(F[1,19]=0.56, P=0.47)$ (Figure 2$)$, nor was there an effect of the order on the change in VAS scores of depressed $\operatorname{mood}(F[1,19]=0.02, P=0.89)$. There was also no interaction between the order and supplement condition (rmANOVA: $F[1,19]=0.80, P=0.38$ ).

Similar results was also observed for POMS depression/ dejection and USS scores. There was a significant increase in POMS depression/dejection scores (POMS3 to POMS4) after sad MIP during supplement (mean \pm SD: 2.95 \pm 4.57 , $t[20]=2.95, P=0.008)$ and placebo (mean \pm SD: $2.19 \pm 3.37$, $t[20]=2.98, P=0.007$ ) conditions (Figure S3). rmANOVA showed that the change in POMS depression/dejection in the active and placebo conditions did not differ significantly, $(F[1,19]=0.002, P=0.97)$, nor was there an effect of the order on the change in POMS depression scores $(F[1,19]=3.26$, $P=0.09$ ). However, there was a significant interaction between the order and effect of supplement, (rmANOVA: $F[1,19]=5.82, P=0.02$ ) which was attributable to a greater effect of the MIP on the first visit with placebo as compared to the second visit with placebo as found on a post-hoc independent $t$-test $(t[19]=4.23, P<0.005)$.

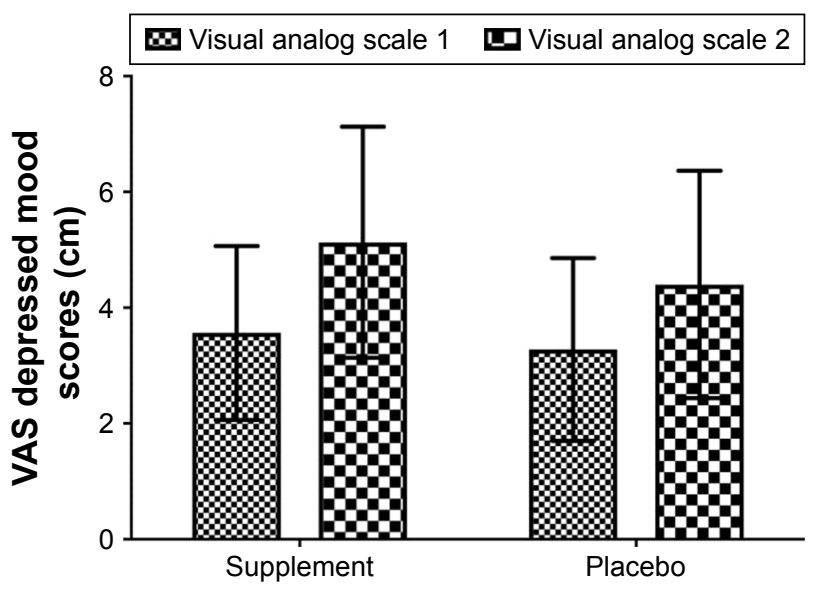

Figure 2 Significant increase in VAS depressed mood scores after the sad MIP during supplement (mean $\pm S D$ : $1.56 \pm 2.09 \mathrm{~cm}, t[20]=3.43$ ) and Placebo (mean $\pm S D: 1.12 \pm 1.81 \mathrm{~cm}, t[20]=2.84$ ) but no effect of dietary supplement in reducing vulnerability to sad mood after sad MIP compared to placebo (rmANOVA: $F[1,19]=0.56, P=0.47)$.

Abbreviations: VAS, visual analog scale; MIP, mood induction procedure; rmANOVA, repeated-measures ANOVA. 
$\mathbf{B}$ Urge to smoke scale $1 \mathbf{\square}$ Urge to smoke scale 2

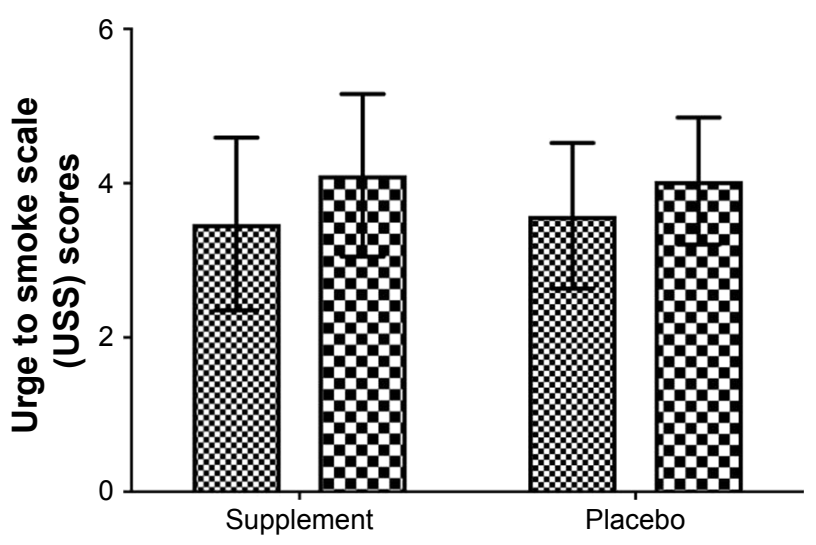

Figure 3 Significant increase in USS scores after sad MIP during supplement (mean \pm SD: $0.63 \pm 0.83, t[20]=3.50$ ) and placebo (mean \pm SD: $0.45 \pm 0.68, t[20]=3.04$ ) with no differences between the groups for change in USS scores (rmANOVA: $F[I, 19]=0.72, P=0.41)$.

Abbreviations: USS, urge-to-smoke scores; MIP, mood induction procedure; rmANOVA, repeated-measures analysis of variance.

There was a significant increase in USS scores (USS3 to USS4) after sad MIP during supplement (mean \pm SD: $0.63 \pm 0.83, t[20]=3.50, P<0.005)$ and placebo (mean $\pm \mathrm{SD}$ : $0.45 \pm 0.68, t[20]=3.04, P=0.006)$. The differential change in USS between the active and placebo conditions was not significant, (rmANOVA: $F[1,19]=0.72, P=0.41$ ) (Figure 3), nor was there an effect of the order on MIP (rmANOVA: $F[1,19]=0.58, P=0.45)$. There was also no interaction between the order and supplement conditions (rmANOVA: $F[1,19]=0.25, P=0.62)$. Review of USS scores over the individual time points showed a steady increase in scores over time (see Figure S2).

In order to assess whether the difference in VAS from one assessment to the next was not similar, a difference score for VAS was calculated between each subsequent assessment. rmANOVA assessing the difference scores found that the difference scores were unequal $(F[2.91,100]=5.84, P=0.002)$. A similar approach was taken for the USS to assess whether there were sequential differences in USS change. A difference score for USS was calculated between each assessment timepoint. Visual inspection of the data did not suggest that the change in USS between assessments differed much over time, with somewhat greater change across time-points 2-3 and 3-4. rmANOVA assessing the difference, including a factor for visit, was a trend only $(F[3,60]=2.592, P=0.061)$.

\section{Reliability of depressed mood induction}

The application of MIP on VAS depressed mood scores between time point four and five (pre and post sad MIP) of depressed mood revealed significant ICC across the repeated measurement $(\mathrm{ICC}=0.72, P=0.003$ ). The rise in VAS scores of depressed mood on the first and second active study days were $47 \%$ and $32 \%$, respectively. There was also a strong, positive correlation between the change in VAS mood scores on both active study days, which was statistically significant $\left(r=0.57, \mathrm{~N}=21, P=0.007, R^{2}=0.32\right)$ (Figure 4).

\section{Discussion}

To our knowledge, this is the first study to evaluate a dietary supplement consisting of tryptophan, tyrosine and blueberry juice with blueberry extract for reducing sad mood in early cigarette withdrawal and the first to apply the MIP in early cigarette withdrawal. Although there was no effect of the supplement on vulnerability to depressed mood, the MIP robustly and reliably induced depressed mood during early withdrawal.

The lack of effect of the dietary supplement combination in reducing sad mood is unlikely to be accounted for by the study methodology. Increasing the sample size with the present protocol would have a low probability of affecting the outcome; the change in depressed mood was $0.44 \mathrm{~cm}$ greater in the active condition (it was worse in the active condition). The $95 \%$ CI for the differential effect of the condition was -0.32 to $1.2 \mathrm{~cm}$; hence the probability of a true benefit from the supplement in reducing the MIP effect by more than $0.32 \mathrm{~cm}$ was less than $2.5 \%$. This is a low value in the clinical setting, representing only $3 \%$ of the range of the scale. For example, differential effects between groups in other studies with the MIP procedure include a greater effect of $3.5 \mathrm{~cm}$ in early postpartum compared to women not recently pregnant, and a $4.3 \mathrm{~cm}$ effect in favor of active supplement over placebo in early postpartum. The intake of the supplement was adequate since the compliance rate was high at $100 \%$ for the supplement consumption, and both tryptophan and tyrosine supplements at this dose increase plasma levels approximately five to sevenfold. ${ }^{32,33,47}$ Similar tryptophan and tyrosine administration at doses influencing plasma levels similarly are known to strongly elevate tryptophan and tyrosine in the cerebrospinal fluid, as well as, elevate metabolites of serotonin and dopamine in the cerebrospinal fluid. ${ }^{48-53}$ The amount of blueberry anthocyanins in the extract given corresponded to high-end dietary intake of blueberries and blueberries have a wide range of anthocyanins which tend to be brain penentrant. ${ }^{36,38}$ For example, Janle et al reported that gavage administered [14C]labeled anthocyanins are present in rodent brain 24 hours later at $\sim 2 \%$ dose per gram. ${ }^{54}$ Although key issues of sample size, compliance and supplement composition appear addressed 


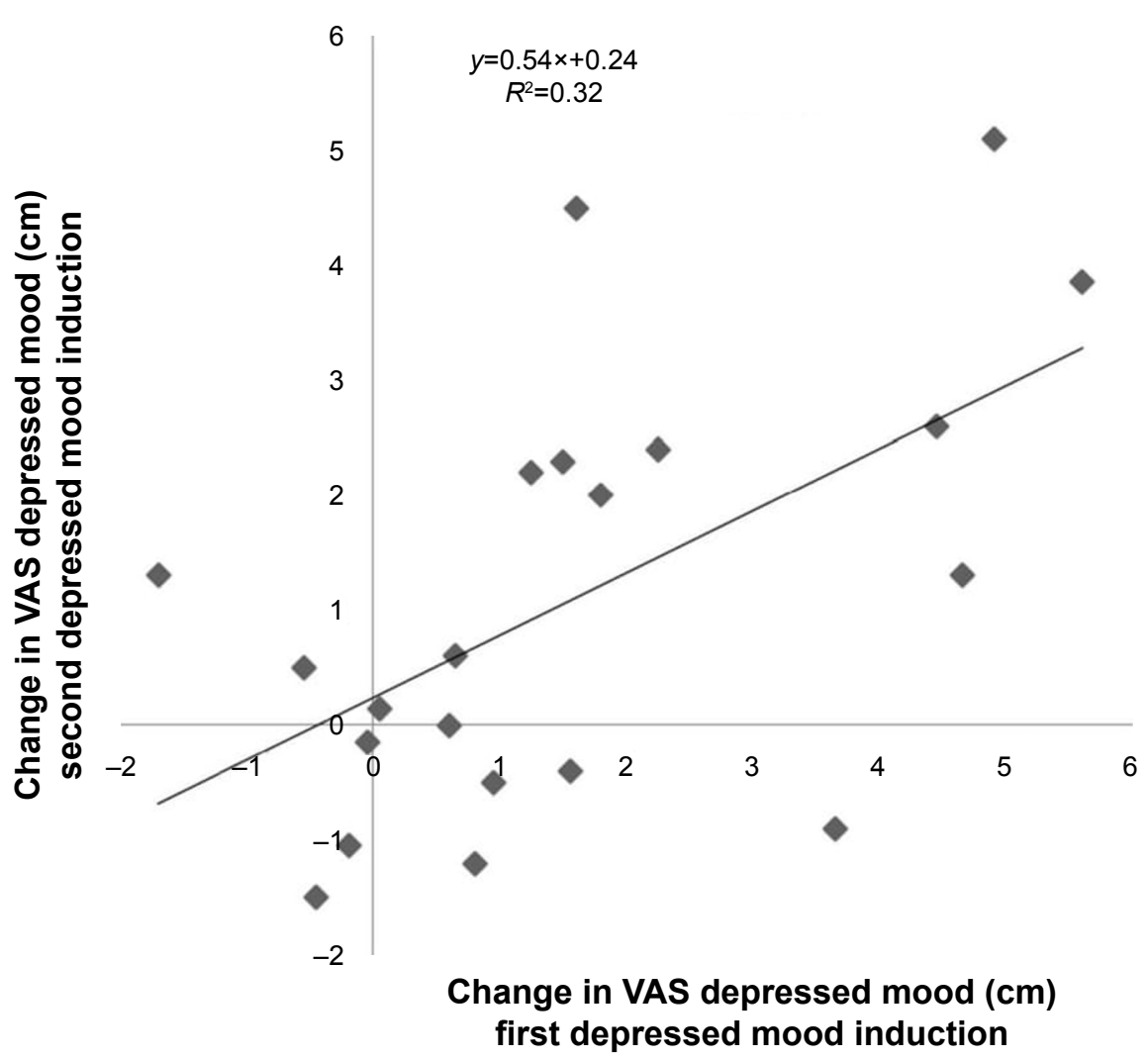

Figure 4 Significant correlation between the change in VAS depressed mood scores on both active study visits (Pearson $r=0.57, P=0.007, R^{2}=0.32$ ). $B$ (degree of slope) in regression is 0.54 .

Abbreviation: VAS, visual analog scale.

in the study design, an issue that could be considered for future studies is whether longer term administration of the supplement prior to or after withdrawal would reduce depressed mood. This supplement was strikingly impactful in an open trial in postpartum blues, ${ }^{55}$ another condition associated with elevated MAO-A level, with an effect size of 2.9; but there are several reasons why this supplement may not necessarily reduce the impact of the MIP in early cigarette withdrawal. Plausible reasons are that the elevation of the index of MAO-A level in the prefrontal and anterior cingulate cortex of early cigarette withdrawal is of lesser magnitude compared to early postpartum ( $25 \%$ vs $43 \%)$, ${ }^{22}$ and it is likely that there is a broader range of mechanisms that account for depressed mood in withdrawal from cigarette smoking, given that there are over 5,000 chemicals in cigarette smoke. ${ }^{56}$ Also, the magnitude of depressed mood increase after MIP is considerably greater in early postpartum, so there is a larger target for intervention. Hence, the matching of the supplement to the elevation of MAO-A level and its associated vulnerability to MIP, may be inferior for early cigarette withdrawal as compared to early postpartum.
This study demonstrates that sad MIP done by the combination of Velten and music was successful in creating a temporary sad mood state, during early cigarette withdrawal, that was similar over two different testing sessions. There is still a need for a range of rapidly impacting options to prevent sad mood during early cigarette withdrawal. Hence, the sad MIP, an easy, economical measure, that detects vulnerability to sadness in early cigarette withdrawal, ${ }^{57,58}$ could be considered as a tool to assess the effects of other promising interventions for reducing sad mood during early withdrawal, although, given that the effect of MIP on the second visit was lower in magnitude than the first, it is likely that there is a limit for its repeated use in the same subjects (first visit: $1.58 \pm 2.01$, second visit: $1.1 \pm 1.90$ ).

In conclusion, our study does not support use of acute oral monoamine precursors with blueberry juice and extract to reduce depressed mood during early cigarette withdrawal. The study design rules out acute benefits of this combination on depressed mood, although more chronic dosing could be considered. A likely explanation for lack of effect is inadequate match of the supplement to the underlying 
heterogeneous set of mechanisms implicated in the depressed mood induced by cigarette withdrawal. Nevertheless, MIP for depressed mood is a simple and practical method that may be straightforwardly applied to investigate interventions for preventing vulnerability to depressed mood during early cigarette withdrawal.

\section{Author contributions}

All authors contributed to data analysis, drafting and revising the article, gave final approval of the version to be published, and agree to be accountable for all aspects of the work.

\section{Disclosure}

Dr Yekta Dowlati is developing natural health products to overcome high MAO-A state in early postpartum.

Dr Jeffrey H Meyer has been a consultant to Mylan, Lundbeck, Takeda, Teva, and Trius for the past 5 years. He is an inventor with five patents (processed or filed) including blood markers to predict brain inflammation or to diagnose affective disorders, and a dietary supplement to reduce depressed mood post-partum. None of these companies participated in the funding, design or execution of this study or writing the manuscript. Dr Meyer is developing natural health products to treat high risk states for MDE and is the inventor on patent applications for this dietary supplement for preventing depressed mood states.

Dr Peter Selby reports grants from Pfizer Inc./Pfizer Canada Inc., Shoppers Drug Mart, Bhasin Consulting Fund, and Patient-Centered Outcomes Research Institute; has received honoraria for speaking engagements from Pfizer Canada Inc., ABBVie, and Bristol-Myers Squibb and has also received consulting fees from Pfizer Inc./Pfizer Canada Inc., Evidera Inc., Johnson \& Johnson Group of Companies, Medcan Clinic, Miller Medical Communications, MedPlan Communications, NVision Insight Group, Inflexxion Inc., V-CC Systems Inc., Kataka Medical Communications, Sun Life Financial, and Myelin \& Associates. Through an open tender process, Johnson \& Johnson, Novartis, and Pfizer Inc. are vendors of record for providing smoking cessation pharmacotherapy, free/discounted, for research studies.

All the other authors report no conflicts of interest in this work.

\section{References}

1. WHO. WHO Report on the Global Tobacco Epidemic, 2008: The MPOWER Package. Geneva: World Health Organization; 2008.

2. Pratt LA, Brody DJ. Depression in the United States household population, 2005-2006. NCHS Data Brief. 2008;7(7):1-8.
3. Garvey AJ, Bliss RE, Hitchcock JL, Heinold JW, Rosner B. Predictors of smoking relapse among self-quitters: a report from the Normative Aging Study. Addict Behav. 1992;17(4):367-377.

4. Law M, Tang JL. An analysis of the effectiveness of interventions intended to help people stop smoking. Arch Intern Med. 1995;155(18): 1933-1941.

5. Al'absi M, Hatsukami D, Davis GL, Wittmers LE. Prospective examination of effects of smoking abstinence on cortisol and withdrawal symptoms as predictors of early smoking relapse. Drug Alcohol Depend. 2004;73(3):267-278.

6. Hughes JR. Effects of abstinence from tobacco: etiology, animal models, epidemiology, and significance: a subjective review. Nicotine Tob Res. 2007;9(3):329-339.

7. Carey MP, Kalra DL, Carey KB, Halperin S, Richards CS. Stress and unaided smoking cessation: a prospective investigation. J Consult Clin Psychol. 1993;61(5):831-838.

8. Kenford SL, Smith SS, Wetter DW, Jorenby DE, Fiore MC, Baker TB. Predicting relapse back to smoking: contrasting affective and physical models of dependence. J Consult Clin Psychol. 2002;70(1): 216-227.

9. Hughes JR. Effects of abstinence from tobacco: valid symptoms and time course. Nicotine Tob Res. 2007;9(3):315-327.

10. Covey LS, Glassman AH, Stetner F. Depression and depressive symptoms in smoking cessation. Compr Psychiatry. 1990;31(4):350-354.

11. Covey LS, Glassman AH, Stetner F, Rivelli S, Stage K. A randomized trial of sertraline as a cessation aid for smokers with a history of major depression. Am J Psychiatry. 2002;159(10):1731-1737.

12. Saules KK, Schuh LM, Arfken CL, Reed K, Kilbey MM, Schuster CR. Double-blind placebo-controlled trial of fluoxetine in smoking cessation treatment including nicotine patch and cognitive-behavioral group therapy. Am J Addict. 2004;13(5):438-446.

13. Hall SM, Reus VI, Muñoz RF, et al. Nortriptyline and cognitivebehavioral therapy in the treatment of cigarette smoking. Arch Gen Psychiatry. 1998;55(8):683-690.

14. Froeliger B, Mcconnell PA, Stankeviciute N, Mcclure EA, Kalivas PW, Gray KM. The effects of N-Acetylcysteine on frontostriatal resting-state functional connectivity, withdrawal symptoms and smoking abstinence: A double-blind, placebo-controlled fMRI pilot study. Drug Alcohol Depend. 2015;156:234-242.

15. Schmaal L, Berk L, Hulstijn KP, Cousijn J, Wiers RW, van den Brink W. Efficacy of $\mathrm{N}$-acetylcysteine in the treatment of nicotine dependence: a double-blind placebo-controlled pilot study. Eur Addict Res. 2011; 17(4):211-216.

16. Bowen DJ, Spring B, Fox E. Tryptophan and high-carbohydrate diets as adjuncts to smoking cessation therapy. J Behav Med. 1991;14(2): $97-110$.

17. Shiffman S, Johnston JA, Khayrallah M, et al. The effect of bupropion on nicotine craving and withdrawal. Psychopharmacology. 2000; 148(1):33-40.

18. West R, Baker CL, Cappelleri JC, Bushmakin AG. Effect of varenicline and bupropion SR on craving, nicotine withdrawal symptoms, and rewarding effects of smoking during a quit attempt. Psychopharmacology. 2008;197(3):371-377.

19. Teneggi V, Tiffany ST, Squassante L, Milleri S, Ziviani L, Bye A. Effect of sustained-release (SR) bupropion on craving and withdrawal in smokers deprived of cigarettes for 72 h. Psychopharmacology. 2005;183(1):1-12.

20. Laviolette SR, van der Kooy D. The neurobiology of nicotine addiction: bridging the gap from molecules to behaviour. Nat Rev Neurosci. 2004;5(1):55-65.

21. Mineur YS, Picciotto MR. Nicotine receptors and depression: revisiting and revising the cholinergic hypothesis. Trends Pharmacol Sci. 2010;31(12):580-586.

22. Bacher I, Houle S, Xu X, et al. Monoamine oxidase A binding in the prefrontal and anterior cingulate cortices during acute withdrawal from heavy cigarette smoking. Arch Gen Psychiatry. 2011;68(8):817-826. 
23. Berlin I, Saïd S, Spreux-Varoquaux O, et al. A reversible monoamine oxidase A inhibitor (moclobemide) facilitates smoking cessation and abstinence in heavy, dependent smokers. Clin Pharmacol Ther. 1995;58(4):444-452.

24. Fowler JS, Volkow ND, Wang GJ, et al. Brain monoamine oxidase A inhibition in cigarette smokers. Proc Natl Acad Sci US A. 1996;93(24): 14065-14069.

25. Meyer JH, Ginovart N, Boovariwala A, et al. Elevated monoamine oxidase a levels in the brain: an explanation for the monoamine imbalance of major depression. Arch Gen Psychiatry. 2006;63(11):1209-1216.

26. Meyer JH, Wilson AA, Sagrati S, et al. Brain monoamine oxidase A binding in major depressive disorder: relationship to selective serotonin reuptake inhibitor treatment, recovery, and recurrence. Arch Gen Psychiatry. 2009;66(12):1304-1312.

27. Rekkas PV, Wilson AA, Lee VW, et al. Greater monoamine oxidase a binding in perimenopausal age as measured with carbon 11-labeled harmine positron emission tomography. JAMA Psychiatry. 2014;71(8):873-879

28. Johnson S, Stockmeier CA, Meyer JH, et al. The reduction of R1, a novel repressor protein for monoamine oxidase $\mathrm{A}$, in major depressive disorder. Neuropsychopharmacology. 2011;36(10):2139-2148.

29. Meyer JH. Neuroimaging markers of cellular function in major depressive disorder: implications for therapeutics, personalized medicine, and prevention. Clin Pharmacol Ther. 2012;91(2):201-214.

30. Roiser JP, Levy J, Fromm SJ, et al. The effect of acute tryptophan depletion on the neural correlates of emotional processing in healthy volunteers. Neuropsychopharmacology. 2008;33(8):1992-2006.

31. Hasler G, Fromm S, Carlson PJ, et al. Neural response to catecholamine depletion in unmedicated subjects with major depressive disorder in remission and healthy subjects. Arch Gen Psychiatry. 2008;65(5): 521-531.

32. Bel N, Artigas F. Reduction of serotonergic function in rat brain by tryptophan depletion: effects in control and fluvoxamine-treated rats J Neurochem. 1996;67(2):669-676.

33. Bongiovanni R, Newbould E, Jaskiw GE. Tyrosine depletion lowers dopamine synthesis and desipramine-induced prefrontal cortex catecholamine levels. Brain Res. 2008;1190:39-48.

34. Leyton M, Young SN, Pihl RO, et al. Effects on mood of acute phenylalanine/tyrosine depletion in healthy women. Neuropsychopharmacology. 2000;22(1):52-63.

35. Oldman AD, Walsh AE, Salkovskis P, Laver DA, Cowen PJ. Effect of acute tryptophan depletion on mood and appetite in healthy female volunteers. J Psychopharmacol. 1994;8(1):8-13.

36. Andres-Lacueva C, Shukitt-Hale B, Galli RL, Jauregui O, LamuelaRaventos RM, Joseph JA. Anthocyanins in aged blueberry-fed rats are found centrally and may enhance memory. Nutr Neurosci. 2005;8(2): $111-120$.

37. Joseph JA, Denisova NA, Arendash G, et al. Blueberry supplementation enhances signaling and prevents behavioral deficits in an Alzheimer disease model. Nutr Neurosci. 2003;6(3):153-162.

38. Kalt W, Blumberg JB, McDonald JE, et al. Identification of anthocyanins in the liver, eye, and brain of blueberry-fed pigs. J Agric Food Chem. 2008;56(3):705-712.

39. Hogarth L, Mathew AR, Hitsman B. Current major depression is associated with greater sensitivity to the motivational effect of both negative mood induction and abstinence on tobacco-seeking behavior. Drug Alcohol Depend. 2017;176:1-6.

40. Fucito LM, Juliano LM. Depression moderates smoking behavior in response to a sad mood induction. Psychol Addict Behav. 2009; 23(3):546-551.
41. Fagerström KO. Measuring degree of physical dependence to tobacco smoking with reference to individualization of treatment. Addict Behav. $1978 ; 3(3-4): 235-241$.

42. Heatherton TF, Kozlowski LT, Frecker RC, Fagerström KO. The Fagerström Test for Nicotine Dependence: a revision of the Fagerström Tolerance Questionnaire. Br J Addict. 1991;86(9):1119-1127.

43. Shiffman S, Waters A, Hickcox M. The nicotine dependence syndrome scale: a multidimensional measure of nicotine dependence. Nicotine Tob Res. 2004;6(2):327-348.

44. Brody AL, Mandelkern MA, London ED, et al. Cigarette smoking saturates brain alpha 4 beta 2 nicotinic acetylcholine receptors. Arch Gen Psychiatry. 2006;63(8):907-915.

45. Velten E. A laboratory task for induction of mood states. Behav Res Ther. 1968;6(4):473-482.

46. Clark DM. The Velten Mood Induction Procedure and cognitive models of depression: a reply to Riskind and Rholes (1985). Behav Res Ther. 1985;23(6):667-669.

47. Mctavish SF, Cowen PJ, Sharp T. Effect of a tyrosine-free amino acid mixture on regional brain catecholamine synthesis and release. Psychopharmacology. 1999;141(2):182-188.

48. Carpenter LL, Anderson GM, Pelton GH, et al. Tryptophan depletion during continuous CSF sampling in healthy human subjects. Neuropsychopharmacology. 1998;19(1):26-35.

49. Williams WA, Shoaf SE, Hommer D, Rawlings R, Linnoila M. Effects of acute tryptophan depletion on plasma and cerebrospinal fluid tryptophan and 5-hydroxyindoleacetic acid in normal volunteers. J Neurochem. 1999;72(4):1641-1647.

50. Growdon JH, Melamed E, Logue M, Hefti F, Wurtman RJ. Effects of oral L-tyrosine administration on CSF tyrosine and homovanillic acid levels in patients with Parkinson's disease. Life Sci. 1982;30(10):827-832.

51. Eccleston D, Ashcroft GW, Crawford TB. Effect of tryptophan administration on 5HIAA in cerebrospinal fluid in man. J Neurol Neurosurg Psychiatry. 1970;33(2):269-272.

52. Fernstrom JD. Effects and side effects associated with the non-nutritional use of tryptophan by humans. J Nutr. 2012;142(12):2236S-2244S.

53. Markus CR, Firk C, Gerhardt C, Kloek J, Smolders GF. Effect of different tryptophan sources on amino acids availability to the brain and mood in healthy volunteers. Psychopharmacology. 2008;201(1):107-114.

54. Janle EM, Lila MA, Grannan M, et al. Pharmacokinetics and tissue distribution of 14C-labeled grape polyphenols in the periphery and the central nervous system following oral administration. J Med Food. 2010;13(4):926-933.

55. Dowlati Y, Ravindran AV, Segal ZV, Stewart DE, Steiner M, Meyer JH. Selective dietary supplementation in early postpartum is associated with high resilience against depressed mood. Proc Natl Acad Sci US A. 2017;114(13):3509-3514.

56. Talhout R, Schulz T, Florek E, van Benthem J, Wester P, Opperhuizen A. Hazardous compounds in tobacco smoke. Int J Environ Res Public Health. 2011;8(2):613-628.

57. Dowlati Y, Segal ZV, Ravindran AV, Steiner M, Stewart DE, Meyer JH. Effect of dysfunctional attitudes and postpartum state on vulnerability to depressed mood. J Affect Disord. 2014;161:16-20.

58. Segal ZV, Kennedy S, Gemar M, Hood K, Pedersen R, Buis T. Cognitive reactivity to sad mood provocation and the prediction of depressive relapse. Arch Gen Psychiatry. 2006;63(7):749-755. 


\section{Supplementary materials}
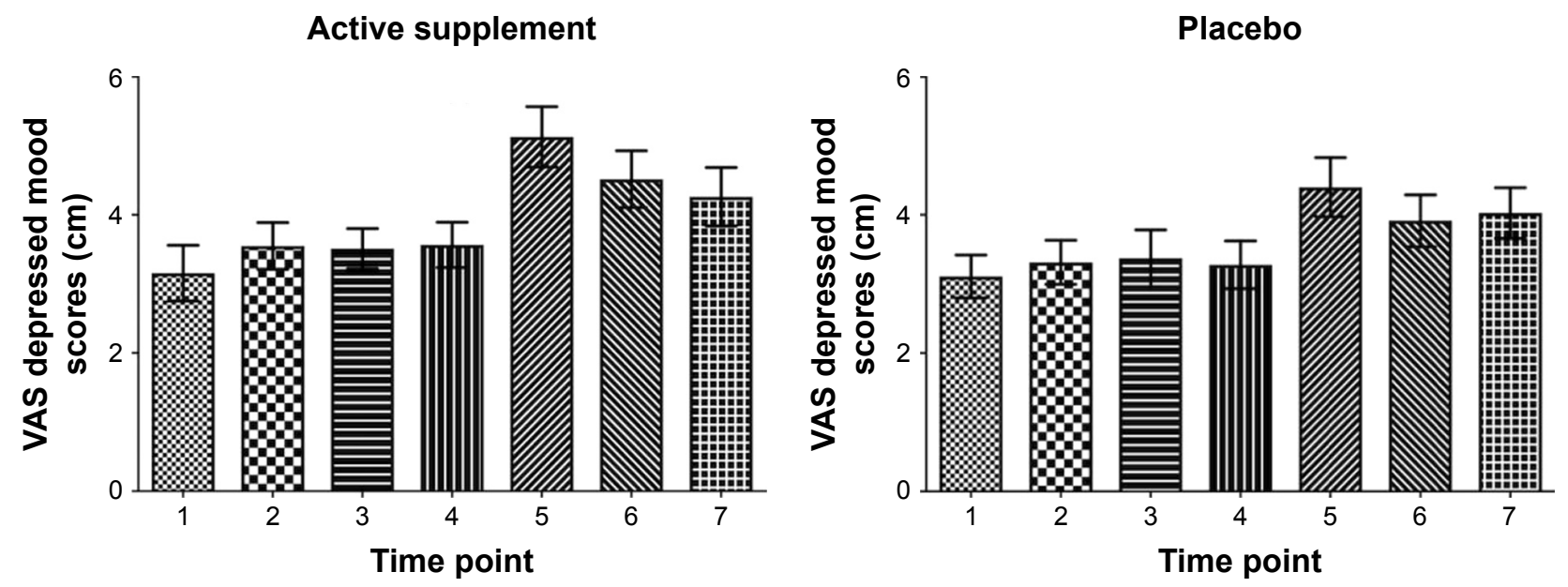

Figure SI Visual analog scale (VAS) mood scores in subjects receiving active dietary supplement and placebo. The sad mood induction procedure was done between time points 4 and 5. (Time points correspond to: $I=7: 35 \mathrm{am}, 2=8: 40 \mathrm{am}, 3=10: 10 \mathrm{am}, 4=11: 20 \mathrm{am}, 5=12.25 \mathrm{pm}, 6=13: 10 \mathrm{am}, 7=14: 30)(\mathrm{Data}$ shown as mean and standard error).

Active supplement

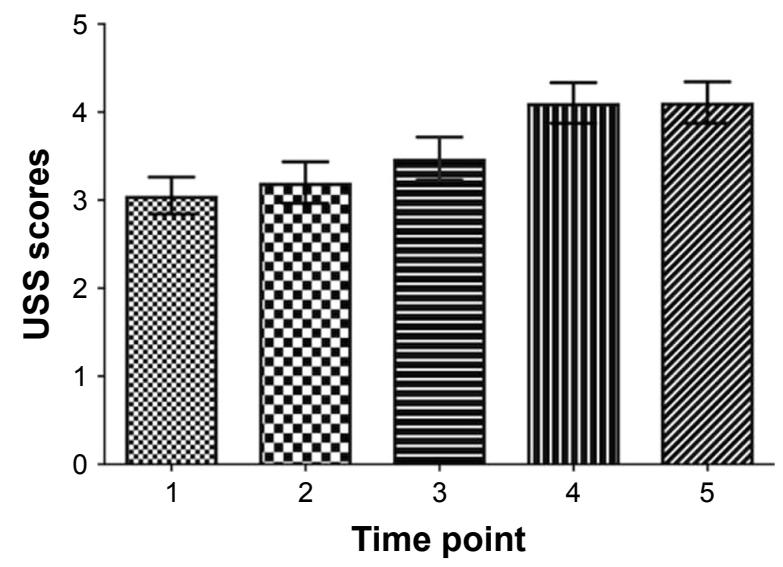

Placebo

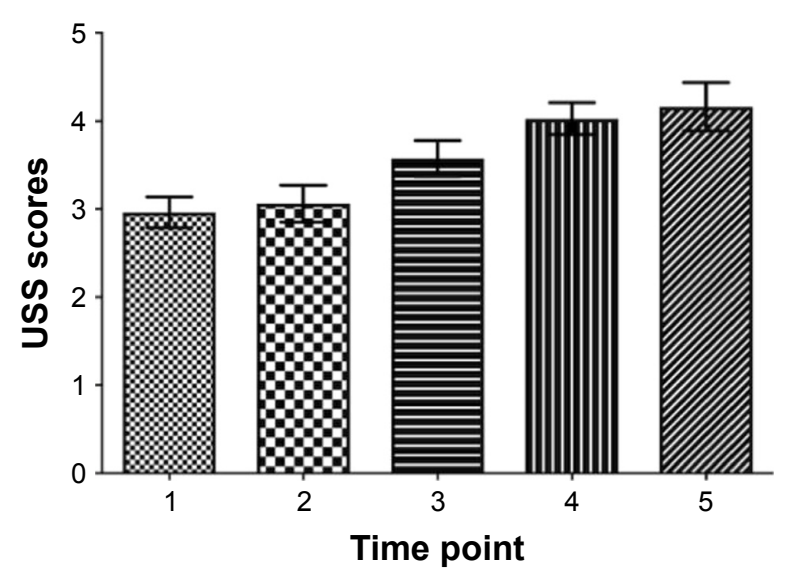

Figure S2 Urge to smoke scale (USS) scores in subjects receiving active dietary supplement and placebo. The sad mood induction procedure was done between time points 3 and 4. (Time points correspond to: I=7:35 am, 2=8:40 am, 3=II:20 am, 4=12.25 pm, 5=14:30 pm) (Data shown as mean and standard error).

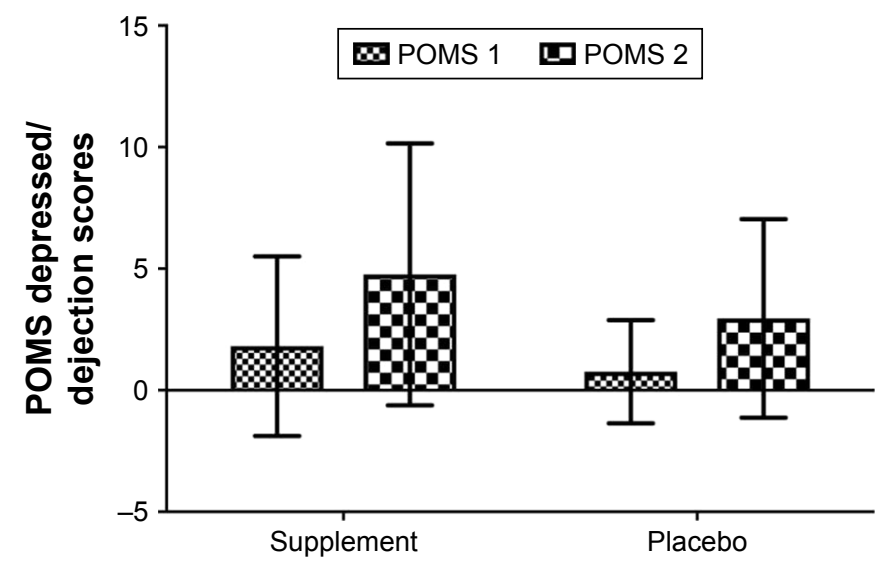

Figure S3 Significant increase in profile-of-mood-state (POMS) scale depression/dejection score after sad mood induction procedure (MIP) during supplement (mean \pm SD: $2.95 \pm 4.57, t[20]=2.95, P=0.008$ ) and placebo (mean $\pm S D: 2.19 \pm 3.37, t[20]=2.98, P=0.007$ ), but no effect of dietary supplement in reducing vulnerability to sad MIP compared to placebo conditions $(F[1,19]=0.002, P=0.97)$. 


\section{Publish your work in this journal}

Neuropsychiatric Disease and Treatment is an international, peerreviewed journal of clinical therapeutics and pharmacology focusing on concise rapid reporting of clinical or pre-clinical studies on a range of neuropsychiatric and neurological disorders. This journa is indexed on PubMed Central, the 'PsycINFO' database and CAS, and is the official journal of The International Neuropsychiatric Association (INA). The manuscript management system is completely online and includes a very quick and fair peer-review system, which is all easy to use. Visit http://www.dovepress.com/testimonials.php to read real quotes from published authors.

\footnotetext{
Submit your manuscript here: http://www.dovepress.com/neuropsychiatric-disease-and-treatment-journal
} 